\title{
SEPARATION OF ALCOHOL AQUEOUS SOLUTIONS BY REVERSE OSMOSIS AND PERVAPORATION USING A POLY- (1-TRIMETHYLSILYL-1-PROPYNE) MEMBRANE
}

\author{
SHINOBU TANIMURA, KeIJI YAMAGUCHI, SHIN-ICHI NAKAO \\ AND SHOJI KIMURA \\ Department of Chemical Engineering, Faculty of Engineering, \\ University of Tokyo, Bunkyo-ku, Tokyo 113
}

\begin{abstract}
Key Words: Membrane Separation, Reverse Osmosis, Alcohol Aqueous Solution, Poly(1-trimethylsilyl-1propyne)

Ethanol and 1-propanol aqueous solutions were separated by reverse osmosis (RO) and pervaporation (PV) using a poly(1-trimethylsilyl-1-propyne) (PTMSP) membrane, and the membrane showed alcohol selectivity in both RO and PV. Flux decreased with time but selectivity did not change in PV. On the other hand, both flux and selectivity were constant with time in RO. Spiegler-Kedem's equations predicted that the alcohol selectivity in Ro significantly increased with increase in operating pressure.
\end{abstract}

\section{Introduction}

For the membrane separation of alcohol aqueous solution, there are two kinds of membranes: alcoholpermselective and water-permselective membranes. It is considered that in practical application of alcohol separation from dilute aqueous solution, the alcohol-selective membrane is more effective than the water-selective one. This is due to the fact that large amounts of water must permeate the membrane when the water-selective membrane is used, while if the membrane is alcohol-selective, the amount of alcohol permeating the membrane is small.

Recently, ethanol-selective membranes for perva-

Received March 19, 1992. Correspondence concerning this article should be addressed to $\mathrm{S}$. Tanimura. poration (PV) (silicone rubber ${ }^{3,11)}$, poly(1-trimethylsilyl-1-propyne) (PTMSP) ${ }^{1}$, and modified PTMSP6-8) membranes) have been reported. However, only the n-hexyldimethylsilylated PTMSP (Hexyl-PTMSP) membrane has been reported to show ethanol selectivity in reverse osmosis ( $\mathrm{RO}$ ) of ethanol aqueous solution. ${ }^{13)}$ Hence, we performed RO separations of ethanol aqueous and 1-propanol aqueous solutions using the PTMSP membrane. PV experiments were also carried out for comparison with the results of $\mathrm{RO}$.

It is reported that gas permeability of PTMSP decreases with aging (heat treatment ${ }^{12)}$ or treatment in a vacuum ${ }^{9,15)}$ ). Hence, the stability of the PTMSP membrane in RO and PV was also investigated in this study. 


\section{Experimental}

\subsection{Membrane preparation}

PTMSP was synthesized by the method described by Takada et al. ${ }^{12)}$ The number- and weight-average molecular weights were $6.5 \times 10^{5}$ and $14.8 \times 10^{5}$, respectively. The molecular weight was determined by gel permeation chromatography using standard polystyrenes for calibration. Polymer structure is shown in Fig. 1. A toluene solution of PTMSP of about $1.2 \mathrm{wt} \%$ was cast on a polytetrafluoroethylene sheet and the toluene was evaporated over 24 hours at room temperature and atmospheric pressure. The thickness of the dry membranes was $40-50 \mu \mathrm{m}$.

\subsection{Reverse osmosis}

A batch-type cell with an effective membrane permeation area of $19.6 \mathrm{~cm}^{2}$ was used. The feed solution was pressurized from $3.9 \mathrm{MPa}$ to $7.8 \mathrm{MPa}$ by nitrogen gas and stirred with a magnetic stirrer. The feed temperature was maintained at $30^{\circ} \mathrm{C}$. The experiment was performed in the order of decreasing alcohol concentration in the first step and in the reverse order in the second step. When the feed concentration was changed, feed solution was depressurized to atmospheric pressure. It took about 12 hours to complete the first and second steps.

\subsection{Pervaporation}

A batch-type cell with an effective membrane permeation area of $26.4 \mathrm{~cm}^{2}$ was used. The feed solution at $30^{\circ} \mathrm{C}$ was stirred with a stirrer bar. Pressure on the permeate side was kept at 1-3 torr (133-399 Pa) using a vacuum pump, and the permeate vapor was trapped using liquid nitrogen. The order of the change in feed concentration is the same as that in RO. The feed concentration was changed keeping the pressure on the permeate side at 1-3 torr. It took about 12 hours to complete the first and second steps in PV, as in $\mathrm{RO}$.

\section{Results and Discussion}

\subsection{Stability of PTMSP membrane}

The time dependence of the flux of pure ethanol is shown in Fig. 2. The plots labelled "1st day" indicate the flux at the pressure of $7.8 \mathrm{MPa}$ measured immediately after ethanol was poured into the cell. When the measurements of the "1st day" were finished, the pressure was set at atmospheric pressure. At intervals of about 20 hours, the " 2 nd day" measurement was begun. The " 3 rd day" measurement was conducted about 20 hours after the " 2 nd day" measurement. The results of " 1 st day" measurements imply that the structure of the membrane reaches its equilibrium appropriate to the pressure of $7.8 \mathrm{MPa}$ within 30-60 minutes. The increase in the flux of the "2nd day" from that of the " 1 st day" can be attributed to the swelling of the membrane in the presence of

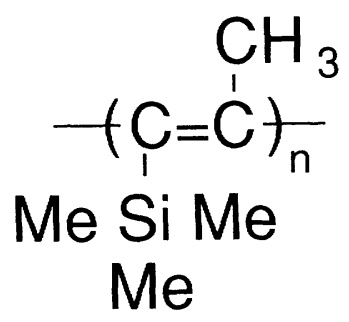

Fig. 1. Molecular structure of PTMSP

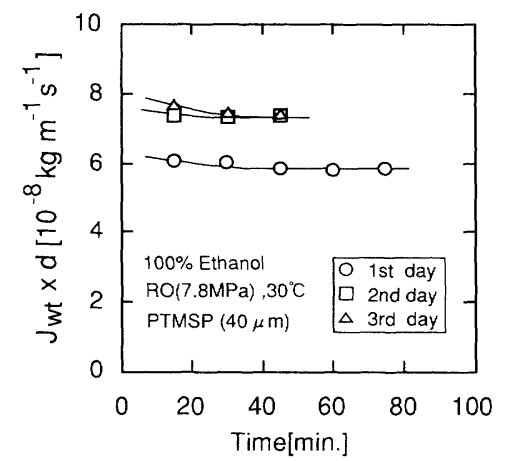

Fig. 2. Time dependence of pure ethanol flux

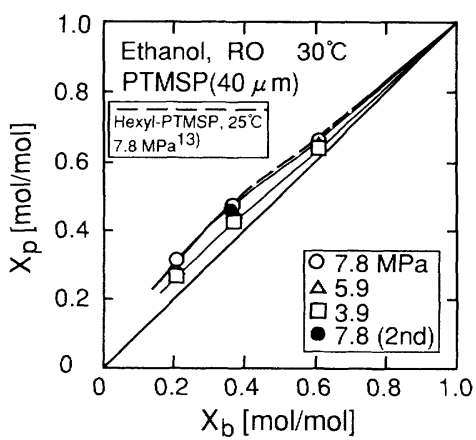

Fig. 3. Ethanol concentration: in the permeate, $X_{p}$, vs. in the bulk feed, $X_{b}$, for RO

ethanol. Perhaps the weakly tangled points of the membrane polymer are disentangled by the swelling. The structural change by the swelling is thought to be completed in 2 days because the flux of the " 3 rd day" is equal to that of the "2nd day". Hence, RO and PV experiments were performed after the membrane was immersed in ethanol over 2 days at room temperature. 3.2 Results of RO and PV experiments

Alcohol concentration of permeate solution and weight flux for RO are shown in Figs. 3 and $\mathbf{4}$ for ethanol solution and Figs. 5 and 6 for 1-propanol solution. The difference between the flux of pure ethanol at $7.8 \mathrm{MPa}$ in Figs. 2 and 4 is attributed to the difference in lot of the membrane. The PTMSP membrane shows ethanol selectivity in RO as does the Hexyl-PTMSP membrane. ${ }^{13)}$ The PTMSP membrane shows high 1-propanol selectivity. The closed keys denote the results of the second step of measurement. Both flux and selectivity are demon- 


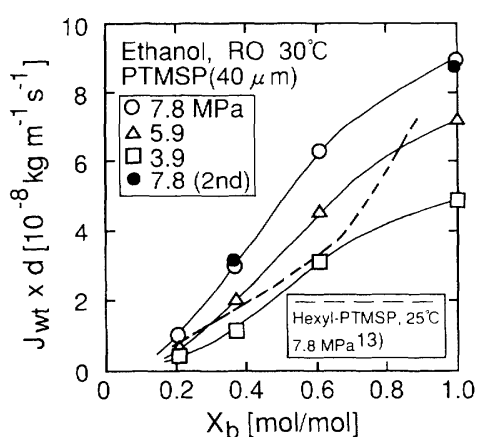

Fig. 4. Dependence of total weight flux multiplied by membrane thickness, $J_{w t} \times d$, on ethanol concentration in the bulk feed, $X_{b}$ for RO

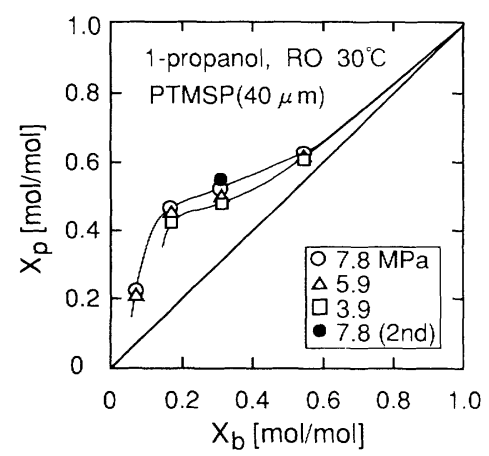

Fig. 5. 1-Propanol concentration: in the permeate, $X_{p}$, vs. in the bulk feed, $X_{b}$, for RO

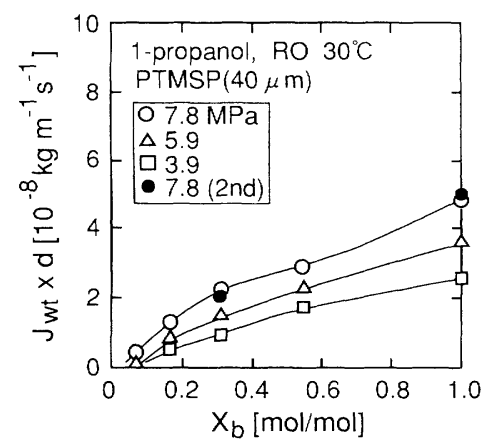

Fig. 6. Dependence of total weight flux multiplied by membrane thickness, $J_{w t} \times d$, on 1-propanol concentration in the bulk feed, $X_{b}$, for RO

strated not to change during the RO experiment. This membrane is stable in the presence of both ethanol and 1-propanol after immersion in ethanol for over 2 days. The increase in flux with increase in alcohol concentration can be attributed to membrane swelling and the decrease in the difference in osmotic pressure throughout the membrane. Measurements of flux and permeate concentration could not be made below a feed concentration of $0.2 \mathrm{~mol} / \mathrm{mol}$ for ethanol and $0.07 \mathrm{~mol} / \mathrm{mol}$ for 1-propanol since the flux becomes too small.

Figures 7-10 show the alcohol concentration of the permeate solution and weight flux for PV. The

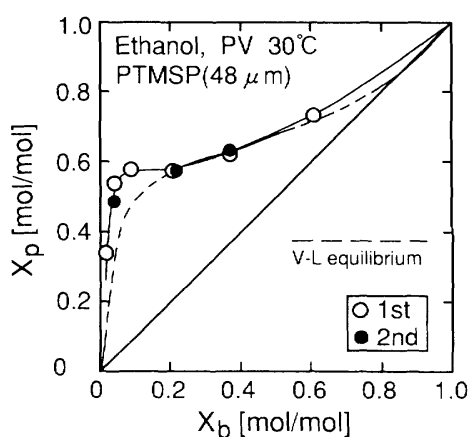

Fig. 7. Ethanol concentration: in the permeate, $X_{p}$, vs. in the bulk feed, $X_{b}$, for PV

Dotted line shows vapor-liquid equilibrium at $30^{\circ} \mathrm{C}$.

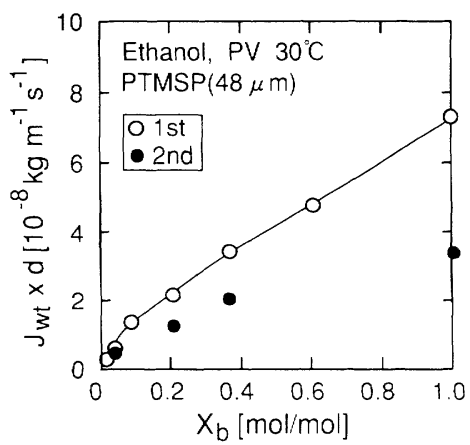

Fig. 8. Dependence of total weight flux multiplied by membrane thickness, $J_{w t} \times d$, on ethanol concentration in the bulk feed, $X_{b}$, for PV

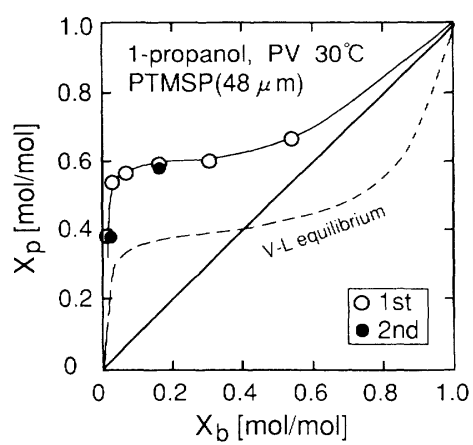

Fig. 9. 1-Propanol concentration: in the permeate, $X_{p}$, vs. in the bulk feed, $X_{b}$, for PV

Dotted line shows vapor-liquid equilibrium at $30^{\circ} \mathrm{C}$.

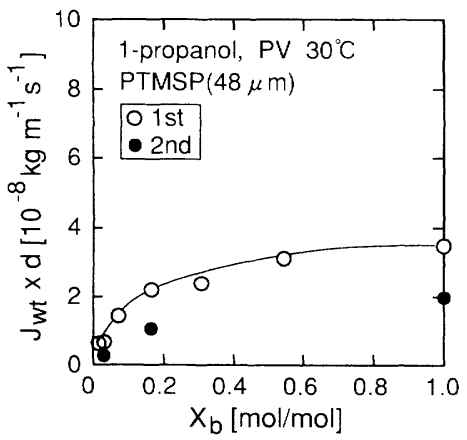

Fig. 10. Dependence of total weight flux multiplied by membrane thickness, $J_{w t} \times d$, on 1-propanol concentration in the bulk feed, $X_{b}$, for PV 
selectivities are higher than those of RO for both ethanol and 1-propanol aqueous solutions. The selectivities do not change during the PV experiment. However the flux in the second step of measurement decreases to about one-half of the results in the first step. The decrease in flux is thought to result from the vacuum condition in the permeate side, because flux does not decrease in RO in which the permeate side is filled with the permeate solution. The flux at $X_{b}=0.38$ in the second step in Fig. 8 did not change even if the membrane was immersed for a week in the feed solution at room temperature and atmospheric pressure. With respect to the gas permeability, the decrease in permeability with aging is suggested to be due to structural relaxation..$^{9,12,15)}$ The density of PTMSP increases with aging. ${ }^{15)}$ Takada et al. ${ }^{12)}$ showed that permeability of oxygen, $P_{\mathrm{O}_{2}}$, decreased and the permeability ratio, $P_{\mathrm{O}_{2}} / P_{\mathrm{N}_{2}}$, increased with heat treatment at $100^{\circ} \mathrm{C}$ for the PTMSP membrane. In the separation of alcohol aqueous solution, the sorption selectivity is expected to increase with relaxation. However, the diffusivity of alcohol is expected to decrease to a greater extent than that of water by relaxation because the molecular size of alcohol is larger than that of water. Hence, the influence of aging on alcohol selectivity is complicated. Under the conditions of this study, although the flux decreases, the selectivity does not change in PV. The flux and selectivity in RO at infinite pressure are equal to those in PV if it is assumed that the membrane behaves as a liquid and that the interaction between the transport species can be ignored. ${ }^{2,5}$ However, the flux of pure alcohol in RO at $7.8 \mathrm{MPa}$ is higher than that in PV, as shown in Figs. 4, 6, 8 and 10. One of the reasons for this phenomenon is considered to be the rigidity of the PTMSP membrane. It is thought that the assumption that the membrane behaves as a liquid is not valid for the PTMSP membrane.

As shown in Fig. 3, ethanol selectivity in RO is smaller than that in PV and that of 1-propanol in RO and PV. This lower ethanol selectivity in RO is mainly attributed to the high osmotic pressure of ethanol. The osmotic pressures of ethanol and 1-propanol are shown in Fig. 11. The osmotic pressure is calculated by use of Eqs. (1) and (2):

$$
\begin{gathered}
\pi_{i}=\frac{-\mathscr{R} T \ln a_{i}}{\bar{V}_{i}} \\
a_{i}=\gamma_{i} X_{i},
\end{gathered}
$$

where $\mathscr{R}$ and $T$ are the gas constant and absolute temperature, respectively. $X$ is the molar fraction, and $\gamma$ is the activity coefficient, which can be calculated by use of Wilson's equation ${ }^{16)}$. The molar volume $\bar{V}_{i}$ in the mixture is assumed to be equal to that in pure solution. The parameters used for calculation of $\gamma_{i}$ are

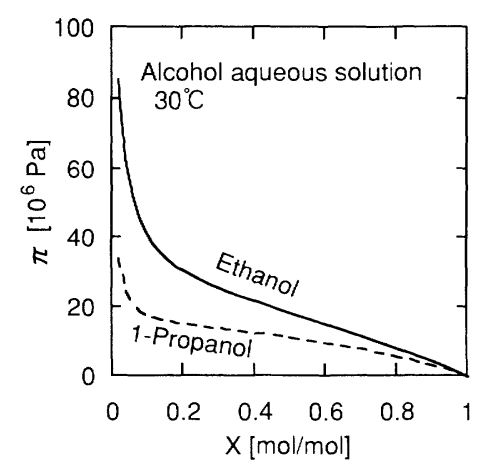

Fig. 11. Osmotic pressure of alcohol in aqueous solution

as follows:

(A) Molar volume in pure solution

$$
\begin{aligned}
& \bar{V}_{i}=18.1 \times 10^{-6} \quad\left[\mathrm{~m}^{3} \mathrm{~mol}^{-1}\right] \quad \text { (water) } \\
& =59.0 \times 10^{-6} \quad \text { (ethanol) } \\
& =75.4 \times 10^{-6} \quad \text { (1-propanol) } \text {. }
\end{aligned}
$$

(B) Wilson parameter ${ }^{4}$

$$
\begin{aligned}
& \text { Ethanol (1)/Water (2); } \\
& \lambda 12-\lambda 11=1641 \quad\left[\mathrm{~J} \mathrm{~mol}^{-1}\right] \\
& \lambda 12-\lambda 22=3825 . \\
& 1-\text { Propanol }(1) / \text { Water }(2) ; \\
& \lambda 12-\lambda 11=3890 \quad\left[\mathrm{~J} \mathrm{~mol}^{-1}\right] \\
& \lambda 12-\lambda 22=5408 .
\end{aligned}
$$

As shown in Fig. 11, the osmotic pressure of ethanol is about twice that of 1-propanol. RO experiments have been performed at pressures below $10 \mathrm{MPa}$ because of the limitation of pressure resistances of the membrane and apparatus. What value of alcohol selectivity can be expected at operating pressures higher than those used in conventional RO? This subject is discussed in the next section.

\section{Alcohol Selectivity Expected at Higher Pressure}

Spiegler and Kedem derived transport equations of RO under the assumption that the solution in the membrane is in equilibrium with an imaginary free solution as ${ }^{10)}$

$$
\begin{gathered}
J_{v}=L_{P}\left(\Delta p-\sigma \Delta \pi_{1}\right) \\
R=\frac{\sigma(1-F)}{1-\sigma F} \\
F=\exp \left(\frac{-(1-\sigma) J_{v}}{P}\right)
\end{gathered}
$$

where $J_{v}$ is total volume flux, $\Delta p$ is operating pressure, and $\Delta \pi_{1}$ is the difference in osmotic pressure of the solvent between the feed side and the permeate side. $R$ is solute rejection. "Solute" denotes water in this 


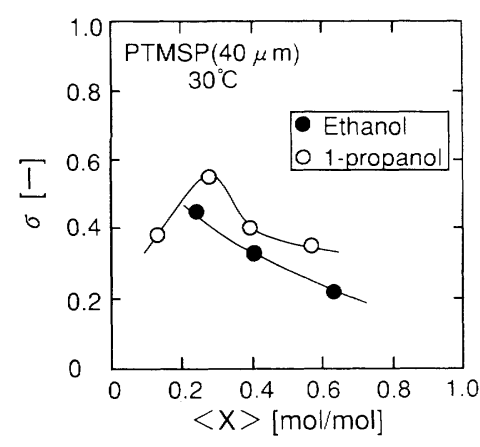

Fig. 12. Reflection coefficient, $\sigma$

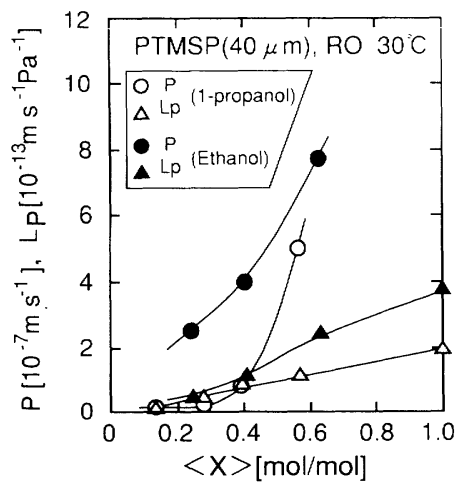

Fig. 13. Solute permeability, $P$ and solvent permeability, $L_{P}$

study. These equations have three parameters: the reflection coefficient $\sigma$, solute permeability $P$ and solvent permeability $L_{P}$. Although these equations were derived for dilute solutions, they can be used for the evaluation of $\mathrm{RO}$ in a wide range of feed concentrations in an approximate manner. ${ }^{14)}$ The membrane parameters $\sigma, P$ and $L_{P}$ determined from the results of RO experiments are shown in Figs. 12 and 13. In these figures the arithmetic mean value between feed concentration and permeate concentration $\langle X\rangle$ is used as the abscissa. The alcohol concentrations in permeate at high pressure can be calculated using Eqs. (1)-(5) and the membrane parameters shown in Figs. 12 and 13.

The calculated alcohol concentrations in permeate at a pressure of $29 \mathrm{MPa}$ are demonstrated in Fig. 14 with the experimental results at a pressure of $7.8 \mathrm{MPa}$. The figure shows that ethanol selectivity can be expected to become much larger with increase in pressure, especially at low feed concentration. The 1-propanol selectivity scarcely increases with increase in pressure because the osmotic pressure is small compared with that of ethanol. However, it is impossible to estimate the alcohol selectivities below 2 concentration of $0.2 \mathrm{~mol} / \mathrm{mol}$ for ethanol and $0.07 \mathrm{~mol} / \mathrm{mol}$ for 1-propanol aqueous solutions because experimental data do not exist, a described above.

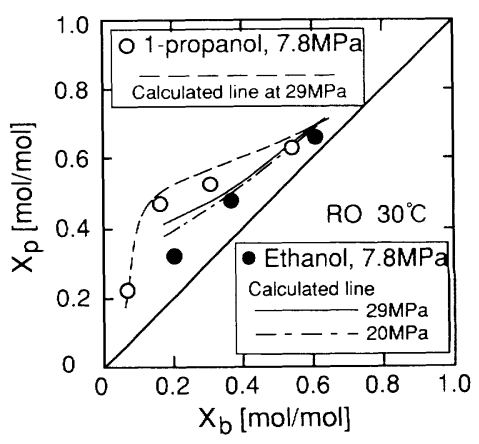

Fig. 14. Alcohol concentration on permeate side calculated by use of Eqs. (3)-(5)

\section{Conclusion}

It was shown that the PTMSP membrane has alcohol selectivity for both ethanol and 1-propanol aqueous solutions in RO as well as in PV.

A decrease in flux with time was observed, but alcohol selectivity did not change in PV. On the other hand, neither flux nor selectivity changed with time in RO.

According to the Spiegler-Kedem equations, ethanol selectivity of the PTMSP membrane in RO is expected to become much larger with increase in pressure.

\section{Acknowledgment}

The authors are grateful to Dr. Y. Nagase at Sagami Chemical Research Center for his help in the preparation of the PTMSP membrane.

\section{Nomenclature}

$\begin{array}{llr}a & =\text { activity } & {[-]} \\ d & =\text { membrane thickness } & {[\mathrm{m}]} \\ L_{P} & =\text { solvent permeability } & {\left[\mathrm{m} \mathrm{s}^{-1} \mathrm{~Pa}^{-1}\right]} \\ p & =\text { pressure } & {[\mathrm{Pa}]} \\ P & =\text { solute permeability } & {\left[\mathrm{m} \mathrm{s}^{-1}\right]} \\ R & =\text { solute rejection } & {[-]} \\ \mathscr{R} & =\text { gas constant } & {\left[\mathrm{J} \mathrm{mol}^{-1} \mathrm{~K}^{-1}\right]} \\ J_{v} & =\text { total volume flux } & {\left[\mathrm{m}^{3} \mathrm{~m}^{-2} \mathrm{~s}^{-1}\right]} \\ J_{w t} & =\text { total weight flux } & {\left[\mathrm{kg} \mathrm{m}^{-2} \mathrm{~s}^{-1}\right]} \\ T & =\text { absolute temperature } & {[\mathrm{K}]} \\ \bar{V} & =\text { molar volume } & {\left[\mathrm{m}^{3} \mathrm{~mol}^{-1}\right]} \\ X & =\text { molar fraction } & {\left[\mathrm{mol}^{2} / \mathrm{mol}^{2}\right]} \\ \gamma & =\text { activity coefficient } & {[-]} \\ \lambda & =\text { Wilson parameter } & {\left[\mathrm{J} \mathrm{mol}{ }^{-1}\right]} \\ \sigma & =\text { reflection coefficient } & {[-]} \\ \pi & =\text { osmotic pressure } & {[\mathrm{Pa}]} \\ \langle\text { Subscripts }\rangle & \\ l & =\text { solvent } & \\ b & =\text { bulk feed } & \\ p & =\text { permeate }\end{array}$

\section{Literature Cited}

1) Ishihara, K., Y. Nagase and K. Matsui, Macromol. Chem. Rapid Commun., 7, 43 (1986).

2) Kataoka, T., T. Tsuru, S. Nakao and S. Kimura, J. Chem. 
Eng. Jpn., 24, 326 (1991).

3) Kimura, S. and T. Nomura, Maku, 8, 177 (1983).

4) Kojima, K., K. Tochigi and K. Kochi, Kagaku-Kogaku, 38, 135 (1974).

5) Lee, C. H., J. Appl. Poly. Sci., 19, 83 (1975).

6) Nagase, Y., K. Sugimoto, Y. Takamura and K. Matsui, J. Appl. Polym. Sci., 43, 1227 (1991).

7) Nagase, Y., Y. Takamura and K. Matsui, J. Appl. Polym. Sci., 42, 185 (1991).

8) Nagase, Y., T. Ueda, K. Matsui and M. Uchikura, J. Polym. Sci. Polym. Phys. Ed., 29, 171 (1991).

9) Shimomura, H., K. Nakanishi, H. Odani, M. Kurata, T. Masuda and T. Higashimura, Kobunshi Ronbunshu, 43, 747
(1986).

10) Spiegler, S. K. and O. Kedem: Desalination, 1, 311 (1966).

11) Suematsu, H., K. Harada and T. Kataoka, Maku, 12, 95 (1987).

12) Takada, K., H. Matsuya, T. Masuda, and T. Higashimura, J. Appl. Polym. Sci., 30, 1605 (1985).

13) Tanimura, S., S. Nakao and S. Kimura, AIChE J., 36, 1118 (1990).

14) Tanimura, S., S. Nakao and S. Kimura: J. Chem. Eng. Jpn., 24, 364 (1991).

15) Tasaka, S., N. Inagaki and M. Igawa, J. Polym. Sci. Polym. Phys. Ed., 29, 691 (1991).

16) Wilson, G. M., J. Am. Chem. Soc., 86, 127 (1964). 